\title{
Pengelolaan Keuangan Dan Perencanaan Usaha Dalam Perspektif Islam
}

\author{
Muharir \\ Program Studi Ekonomi Syariah STEBIS IGM Palembang \\ Email: muharir@stebisigm.ac.id
}

\begin{abstract}
Money is an inseparable part of everyday human life. Money is always used to meet the various necessities of life and to earn the necessary struggles and efforts. Some experts explain that apart from having an original function, money also has a derivative function. The original function of money is as a medium of exchange that can facilitate exchange. People who will make an exchange do not need to exchange money for goods, but simply use it as a medium of exchange. the difficulties of exchange by means of barter can be overcome by the presence of money. To make it easier to get the goods and services needed, humans need a means of payment that can be accepted by everyone, namely money. Second, money as a means of paying debts. Money can be used to measure future payments. Third, as money as a means of hoarding wealth. Money management and business planning are human economic activities whose purpose is survival. This concept has existed for many years, continuing since the days of barter and then to payment systems using money as a means of payment. If applied in today's modern era, money management and business planning are based on future or future needs, people who do business activities and manage money are looking for more profit. However, one should seek profit in a business that is in accordance with Islamic provisions (i.e. avoid gambling, ambiguity and usury).
\end{abstract}

Keywords : Money Management and Business Planning

\begin{abstract}
Abstrak
Uang merupakan bagian yang tidak terpisahkan dalam kehidupan manusia sehari-hari. Uang selalu digunakan untuk memenuhi pelbagai kebutuhan hidup dan untuk mendapatkannya diperlukan perjuangan dan upaya. Beberapa ahli menjelaskan, selain memiliki fungsi asli, uang juga memiliki fungsi turunan. Fungsi asli uang ialah sebagai alat tukar (medium of exchange) yang dapat mempermudah pertukaran. Orang yang akan melakukan pertukaran tidak perlu menukarkan dengan barang, tetapi cukup menggunakan uang sebagai alat tukar. Kesulitan-kesulitan pertukaran dengan cara barter dapat diatasi dengan adanya uang. Untuk mempermudah dalam mendapatkan barang dan jasa yang diperlukan, manusia memerlukan alat pembayaran yang dapat diterima semua orang, yaitu uang. Kedua, uang sebagai alat pembayaran utang. Uang dapat digunakan untuk mengukur pembayaran pada masa yang akan datang. Ketiga, sebagai uang sebagai alat penimbun kekayaan. Pengelolaan uang dan perencanaan usaha adalah kegiatan ekonomi manusia yang tujuanya adalah bertahan hidup. Konsep ini telah ada bertahun tahun lamanya sejak jaman barter dan kemudian berlanjut kepada sistem pembayaran dengan menggunakan uang sebagai alat pembayaran. Jika di aplikasikan di abad modern
\end{abstract}


sekarang ini pengelolaan uang dan perancanaan usaha di dasarkan pada kebutuhan masa depan atau masa yang akan datang pasalanya orang yang melakukan kegiatan usaha dan mengelola uang adalah ingin mencari keuntungan yang lebih. Namun hendaklah mencari keuntungan dalam usaha sesuai dengan ketentuan Islam ( yakni terhindar dari unsur judi, unsur ketidak jelasan dan unsur riba' ).

\section{Kata Kunci: Pengelolaan Uang dan Perencanaan Usaha}

\section{Pendahuluan}

Uang merupakan bagian yang tidak terpisahkan dalam kehidupan manusia sehari-hari. Uang selalu digunakan untuk memenuhi pelbagai kebutuhan hidup dan untuk mendapatkannya diperlukan perjuangan dan upaya. Begitu lekatnya uang dalam kehidupan sehingga muncul pertanyaan populer, 'Apakah Anda hidup untuk uang? atau ,Apakah Anda perlu uang untuk hidup?'. Uang adalah kertas, emas, perak, atau logam mulia lain yang dicetak dan dikeluarkan oleh pemerintah suatu negara sebagai alat penukar atau standar pengukur nilai yang sah. Uang dalam ilmu ekonomi tradisional didefinisikan sebagai alat tukar yang dapat diterima secara umum. Alat tukar itu dapat berupa benda apapun yang dapat diterima oleh setiap orang di masyarakat dalam proses pertukaran barang dan jasa. Ilmu ekonomi modern mendefinisikan uang sebagai sesuatu yang tersedia dan secara umum diterima sebagai alat pembayaran bagi pembelian barang-barang dan jasa-jasa serta kekayaan berharga lainnya serta untuk pembayaran utang (Masruroh, 2012).

Beberapa ahli menjelaskan, selain memiliki fungsi asli, uang juga memiliki fungsi turunan. Fungsi asli uang ialah sebagai alat tukar (medium of exchange) yang dapat mempermudah pertukaran. Orang yang akan melakukan pertukaran tidak perlu menukarkan dengan barang, tetapi cukup menggunakan uang sebagai alat tukar. Kesulitan-kesulitan pertukaran dengan cara barter dapat diatasi dengan adanya uang. Kemudian, uang juga berfungsi sebagai satuan hitung (unit of account) karena uang dapat digunakan untuk menunjukkan nilai pelbagai macam barang/ jasa yang diperjualbelikan, menunjukkan besarnya kekayaan, dan menghitung besar kecilnya pinjaman. Uang juga dipakai untuk menentukan harga barang/ jasa (alat penunjuk harga). Sebagai alat satuan hitung, uang berperan untuk memperlancar pertukaran. Selanjutnya, uang berfungsi sebagai alat penyimpan nilai (valuta) karena dapat digunakan untuk mengalihkan daya beli dari masa sekarang ke masa mendatang. Ketika seorang penjual saat ini menerima sejumlah uang sebagai pembayaran atas barang dan jasa yang dijualnya, maka ia dapat menyimpan uang tersebut untuk digunakan membeli barang dan jasa di masa mendatang. Sedangkan fungsi turunan uang, antara lain: Pertama, uang sebagai alat pembayaran yang sah. Kebutuhan manusia akan barang dan jasa yang semakin. bertambah dan beragam tidak dapat dipenuhi melalui cara tukarmenukar atau barter.

Untuk mempermudah dalam mendapatkan barang dan jasa yang diperlukan, manusia memerlukan alat pembayaran yang dapat diterima semua orang, yaitu uang. Kedua, uang sebagai alat pembayaran utang. Uang dapat digunakan untuk mengukur pembayaran pada masa yang akan datang. Ketiga, sebagai uang sebagai alat penimbun kekayaan. Sebagian orang biasanya tidak menghabiskan semua uang yang dimilikinya untuk keperluan konsumsi. Ada sebagian uang yang disisihkan dan ditabung untuk keperluan di masa datang. Keempat, uang sebagai alat pemindah kekayaan. Seseorang yang hendak pindah dari suatu tempat ke 
tempat lain dapat memindahkan kekayaannya yang berupa tanah dan bangunan rumah ke dalam bentuk uang dengan cara menjualnya. Di tempat yang baru dia dapat membeli rumah yang baru dengan menggunakan uang hasil penjualan rumah yang lama. Kelima, uang sebagai alat pendorong kegiatan ekonomi. Apabila nilai uang stabil orang lebih bergairah dalam melakukan investasi. Dengan adanya kegiatan investasi, kegiatan ekonomi akan semakin meningkat.2 Kepemilikan uang dapat melambangkan kemakmuran, kesejahteraan, atau bahkan kebahagiaan. Uang dapat mewujudkan impian, cita-cita, dan harapan. Robert T. Kiyosaki dalam bukunya, Rich Dad Poor Dad, mengatakan bahwa uang mungkin bukan hal terpenting dalam hidup. Namun, uang memengaruhi segala sesuatu yang penting bagi siapapun. Taraf pelayanan kesehatan yang bisa nikmati, kualitas pendidikan yang dapat diperoleh, dan tentu saja tingkat kualitas hidup yang dapat dijalankan. Pada dasarnya, tujuan penciptaan manusia adalah untuk beribadah kepada Allah Swt., sebagaimana disebutkan dalam Alquran:

Tidaklah Aku ciptakan jin dan manusia kecuali beribadah (mengesakan ibadahnya) kepada-Ku, Aku tidak menghendaki rezeki sedikitpun dari mereka dan Aku tidak menghendaki supaya mereka memberi makan pada-Ku, Sesungguhnya Dialah Allah yang Maha Pemberi rezeki yang mempunyai kekuatan Lagi Maha Sangat Kuat' (Q.s. al-Dzâriyât [51]: 56-58).

Pada ayat diatas dijelaskan bahwa manusia di perintahkan untuk beribadah hanya kepada Allah SWT, semua nggota badan dan panca indra manusia digerakan untuk beribadah. Dengan demikian jelaslah sudah tujuan manusia hidup didunia adalah untuk beribadah dan mencari bekal untuk di akhirat kelak.

Pengelolaan uang dan perencanaan usaha adalah kegiatan ekonomi manusia yang tujuanya adalah bertahan hidup. Konsep ini telah ada bertahun tahun lamanya sejak jaman barter dan kemudian berlanjut kepada sistem pembayaran dengan menggunakan uang sebagai alat pembayaran. Jika di aplikasikan di abad modern sekarang ini pengelolaan uang dan perancanaan usaha di dasarkan pada kebutuhan masa depan atau masa yang akan datang pasalanya orang yang melakukan kegiatan usaha dan mengelola uang adalah ingin mencari keuntungan yang lebih. Namun hendaklah mencari keuntungan dalam usaha sesuai dengan ketentuan Islam ( yakni terhindar dari unsur judi, unsur ketidak jelasan dan unsur riba'). Berbagai penjelasan dari sumber kutipan diatas penulis ingin menyampaikan tentang Pengelolaan Keuangan dan Perencanaan Usaha Dalam Perspektif Islam

\section{Metode Pengabdian}

\section{Strategi Pelaksanaan}

Pada rumusan masalah telah dituliskan bagaiman Pengelolaan Keuangan dan Perencanaan Usaha Dalam Perspektif Islam untuk para anggota KPM PKh di Desa Tirta Makmur Kec. Air Kumbang. Ekonomi yang terjadi saat ini dimasa pandemi Corona atau Covid 19 ini sangat mempengaruhi kadaan sosial ekonomi masyarakat Indonesia terutama masyarakat Desa Tirta Makmur Kecamatan Air Kumbang Kabupaten Banyuasin.

Untuk mengetahui bagaimana Pengelolaan Keuangan dan Perencanaan Usaha Dalam Perspektif Islam untuk para anggota KPM PKh di Desa Tirta Makmur Kec. Air Kumbang .Sebagai bahan untuk mensosialisasikan langkahlangkah yang dilakukan adalah:

1) Memilih tempat yang mau disosialisasi oleh tim PPM

2) Merumuskan metode sosialisasi 
3) Masyarakat disiapkan untuk bertanya kepad tim PPM

2. Persiapan

Dalam melakukan sosialisasi tim PPM melakukan persiapan:

1) Materi yang akan disampaikan

2) Gambaran tentang bagaimana Pengelolaan Keuangan dan Perencanaan Usaha Dalam Perspektif Islam

3) Hard Copy materi yang akan disampaikan.

\section{Realisasi Pelaksanaan Kegiatan}

Pada bab sebelumnya, dikegiatan PPM ini adalah memberikan sosialisasi kepada masyarkat Desa Tirta Makmur Kecamatan Air Kumbang Kabupaten Banyuasin. Dengan adanya sosialisasi ini diharapkan masyarakat di Kecamatan Air Kumbang, dan KPM PKh mampu memahami tentang bagaimana cara bagaimana Pengelolaan Keuangan dan Perencanaan Usaha Dalam Perspektif Islam Sebelum melaksanakan kegiatan sosialisasi ini tim PPM melukan observasi, diskusi dengan kepala desa, Kecamatan Air kumbang, kemudian tim PPM menentukan sasaran PPM, kemudian dilanjukan dengan konsultasi dengan PendampingPKH Kecamatan Air Kumbang. Dan rumah Ketua KPM PKH sebagai tempat sosialisasi tim PPM nantinya. Pelaksanaan kegiatan ini dilaksanakan pada tanggal 04 Juni 2021 dimulai pukul 09:00 s/d 11: 00 dengan tahapan kegiatan mulai dari pengertin apa itu pengelolaan keuangan menurut konsep Islam secara umum, Perencanaan usaha secara umum dan samapi dengan tentang bagaimana cara Pengelolaan Keuangan dan Perencanaan Usaha Dalam Perspektif Islam

\section{Sasaran}

Sasaran dari kegiatan tim PPM adalah masyarakat, anggota KPM PKh Kec. Air kumbang. Dengan bentuk kegiatannya adalah sosialisasi tengang. bagaimana Pengelolaan Keuangan dan Perencanaan Usaha Dalam Perspektif Islam Peserta yang hadir rata- rata merka yang sudah berumur $30 \mathrm{~S}$ s/d 50 tahun.

\section{Tempat dan Metode yang digunakan}

1. Tempat

Adapun tempat pelaksanaan pengabdian Masyarakat adalah Rumah Ketua KPM PKH Kecamtan Air kumbang kabupaten Banyuasin.
a. Nama
: Muharir S.E.I., M.E.Sy
NIDN
: 2115109101
Jabatan
: Dosen
Tempat Tugas : STEBIS IGM PALEMBANG
b. Nama : Choirunisak., S.E.I, M.E
NIDN : 2109029103
Jabatan : Dosen
Tempat Tugas : STEBIS IGM PALEMBANG

2. Metode yang digunakan

Metode yang digunakan dalam pengabdian ini ialah metode pengajaran berbasis pengajaran dalam pendidikan agama Islam diantaranya yaitu;

a. Metode bercerita

Yaitu metode menceritakan tentang keadaan ekonomi Indonesia saat ini dan pola penngelolaan keuangan masyarakat Indonesia saat ini dan mengajak 
masyarakat untuk berfikir tentang bagaimana bagaimana Pengelolaan Keuangan dan Perencanaan Usaha Dalam Perspektif Islam

b. Metode pemberian contoh dan teladan

Yaitu memberikan contoh dan teladan seperti yang dicontohkan oleh baginda Nabi Muhammad saw. Dan mengikuti anjuran pemerintah dari lembaga yang sudah dibentuk yaitu MUI ( Majlis Ulama Indonesia ).

c. Metode Tanya jawab

Metode Tanya jawab ini bertujuan untuk menerapkan prinsip keterbukaan antara masyarakat dan keolmpok serta memberikan wawasan atas jawaban yang telah diberikan oleh tim PPM.

d. Metode perumpamaan

Metode ini digunakan untuk menyampaikan materi tentang kekuasaan tuhan tentang ketentuan baik dan buruk, rezeki dan kematian yang telah ditakdirkan oleh tuhan. Dan tetantang bagaimana Pengelolaan Keuangan dan Perencanaan Usaha Dalam Perspektif Islam

\section{Hasil dan Pembahasan}

\section{Temuan Hasil Evaluasi}

Kegiatan awal yang dilakukan, yaitu berkoordiansi dengan Kades Desa Tirta Makmur Kecamatan Air kumbang, dan kepala dengan Pendamping PKH kecamatan Air Kumbang dan dengan Ketua Kelompok KPM PKh Desa Tirta Makmur Kecamatan Air Kumbang. Setelah melakukan koordinasi dan diskusi, selanjutnya melakukan observasi dan melihat kondisi tempat, serta jumlah masyarakat. Tim PPM selanjutnya memilih tempat Rumah Ketua KPM PKh sebagai tempat sosialisasi kegiatan PPM di desa Tirta Makmur Kecamatan Air Kumbang Kab. Banyuasin.

Kegiatan ini dilaksanakan pada tanggal 04 Juni pad pukul 09:00 s/d 11:00 dan Alhamdulillah dapat berjalan dengan lancar, dan peserta dapat mengikutinya dengan baik dan materipun dapat tersampaikan dengan paripurna namun banyak pertanyaan yang belum dapat terjawab karena keterbatasan waktu.

\section{Pembahasan}

Dari hasil sosialisasi yang dilakukan bahwa selama proses dilaksanakan sosialisasi ini masyarakat memiliki antusias yang sangat besar dalam menyikapi, mendengar dan memahami bagaimana Pengelolaan Keuangan dan Perencanaan Usaha Dalam Perspektif Islam. Karena begitu banyak manfaat yang didapat oleh masyarakat bahwa pengelolaan keuangan menurut perspetif Islam merupan solusi untuk kemaslahatan umat. Dengan demikian pola masyarakat Desa TirtaMakmur dalam mengelola keuangan dan merancanakan usaha diharapkan sesuai dengan tuntunan syariat Islam dan peraturan perundang undangan usaha di Indonesia.

Mengelola uang dan merencanakan sebuah usaha merupakansalah satu pola kehidupan yang baik dan cara mempertahankan hidup yang baik karena dengan merencanakan dan merealisasikan sebuah usaha dan dengan diiringi pengelolaan keuangan yang baik sesuai dengan perspetif Islam maka kita akan terhindar dari perbuatan syetan dan menjadi orang- orang yang merugi dunia maupun diakhirat. Dan orang yang melakukan pola pengaturan keuangan dengan tuntunan Syariat Islam dan Perundang undangan usaha di Indonesia akan memperoleh manfaat diantaranya sebagai berikut:

1. Memeliki pedoman yang jelas

2. Prinsip ekonomi yang bersumber langsung dari tuhan 
3. Dapat terhindari dari Maisir ( Judi ) Gharar ( tidak jelas ) Riba' (

Melipat gandakan )

4. Memberikan efek pengendalian diri

5. Memiliki dasar pemikiran yang jelas dan terarah.

3. Roandown acara

1) Tempat dan Waktu Kegiatan

Kegiatan ini dilaksanakan di Desa Tirta Makmur Kecamatan Air Kumbang sosialisasi ini dilakukan pada Hari/ Tangg: Jum'at s/d sabtu 04 Juni s/d 05 Juni 2021

2) Waktu Kegiatan dan Materi Pokok dalam Kegiatan

Pelaksanaan kegiatan ini dilakukan selama dua (2) hari yaitu hari jumat-Sabtu Adapun jadwalnya adalah sebagai berikut :

Tanggal 04 Juni 2021

\begin{tabular}{|c|lr|l|}
\hline Waktu & \multicolumn{1}{|c|}{ Materi } & \multicolumn{1}{|c|}{ Narasumber } \\
\hline 08.00.-08.30 & Registrasi peserta & Rosyid \\
\hline $08.30 .-10.00$ & Pembukaan & Miftah \\
\hline 02.00.-10.00. & $\begin{array}{l}\text { Pengelolaan Keuangan dan } \\
\text { Perencanaan }\end{array}$ & $\begin{array}{r}\text { Usaha } \\
\text { Dala }\end{array}$ & Muharir, S.E.I, M.E.Sy \\
& mPerspektif Islam & \\
\hline $10.00-11.00$ & Tanya jawab materi & Mode rator \\
\hline
\end{tabular}

\begin{tabular}{|c|l|l|}
\hline $11.00 .-12.30$ & ISHOMA & \\
\hline $12.30-13.30$ & $\begin{array}{l}\text { Pendirian usaha menurut perundang } \\
\text { undangan di Indonesia }\end{array}$ & Muharir, S.E.I, M.E.Sy \\
\hline $13.30-14.00$ & Tanya jawab materi & Moderator \\
\hline $14.00-14.30$ & Penutup dan pembacaan do'a & Ust. Sodikin dan MC \\
\hline
\end{tabular}

\section{Simpulan}

Sebagai akhir dari laporan tim PPM maka dapat disimpulkan sebagai berikut : Sosialisasi ini memberikan pemahaman kepada masyarakat tentang Cara Pengelolaan Keuangan dan Perencanaan Usaha Dalam Perspektif Islam den dengan hasil $90 \%$ masyarakat dapat memahaminya dengan baik dan $10 \%$ masih dalah tahap bimbingan dan pembinaan berikutnya

\section{Saran}

Adapun saran dari PPM ini adanya tindak lanjut terhadap masyarakat dari pihak tim PPM dengan melakukan Evaluasi terhadap para peserta PPM. 


\section{Daftar Pustaka}

Asmawi. (2011). Perbandingan Ushul Fiqh. Jakarta: Amzah.

Affendi, Satria dan M. Zein. (2005). Ushul Fiqh. Prenada Media. Jakarta

Dzulham, (2018). Negara- Negara Dalam Perlindungan Konsumen Muslim Terhadap Produk Halal, Jakarta Timur.

Jumantoro, Totok dan Samsul Munir Amin. Kamus Ilmu Ushul Fiqih. Jakarta:Amzah

Https://elmisbah.wordpress.com/al-maslahah/pengertianalmaslahah Makalah.blogspot.com/2014/10/makalah-mashlahah-almursalah.html 
Muharir 